\title{
Children Unwelcome - Socio-physical Study of Children's Community Toilets Usage in Mumbai's Slums
}

\author{
Tamar Akov ${ }^{1}$ and Sunanda Satwah ${ }^{2}$
}

\begin{abstract}
In light of growing concerns among experts to achieve SDG 6.2 by 2030, and in view of the Swachh Bharat Mission - an initiative launched in 2014 to eradicate open defecation (OD) in India, this field research-based paper sets out to explore the physical and social enabling environment for children of informal settlements in Mumbai to use communal toilets. First stage of the research involved shortlisting 6 community toilets across 3 informal settlements and documenting them for spatial conditions and user experience. 2nd stage consisted of data collection from 986 random samples across all ages and genders, regarding usage patterns. The findings revealed that only $6.7 \%$ of the users were children. This led to the 3rd stage, where 80 children ages 14 and younger were interviewed, to understand their concerns, perceptions, habits and related interactions with adults. The research, spanning 18 months, exposed deficiency in the enabling environment to promote and sustain usage of toilets and diminish OD. Especially for children, the research revealed aspects of discrimination in the form of inequity bylaws; inappropriate ergonomics; adult intimidation; and parental indifference to sanitary choices. The paper suggests systemic children-specific mitigations, thereby lending a voice to their unique concerns and needs.
\end{abstract}

Keywords: Children's Sanitation, Enabling Environment, Discrimination \& Exclusion, SDG 6.2, informal settlements

\section{Introduction}

Whether driven by rising economic prosperity or by other demographic shifts, urbanization in the global south presents great opportunities for advancement in many of the Sustainable Development Goals (SDGs), (UN DESA, 2014). However, increasing urbanization has also brought a significant growth in informal settlements or slums. According to UN Habitat there are at least 881 million people living in slums which are "emerging as a dominant and distinct type of settlement in the cities of the developing world" (UNHABITAT, 2014, 2016) - a demographic shift which is bringing formidable challenges to social equity, environmental sustainability and governance (Bahadure \& Bahadure, 2012). The increasing pressures caused by these shifts are especially apparent in the limited access to basic sanitation services and hygiene in these regions (CSDH, 2008). In order to address this critical issue, the UN Sustainable Development Goal (SDG)-6.2 calls for "access to adequate and equitable sanitation and hygiene for all and to end open defecation, paying special attention to the needs of women and girls and those in vulnerable situations" by 2030 (UN DESA 2014).

Although, the percentage of India's urban users of at least a 'basic sanitation services' within the household increased from 2010 to 2015 by 27\% (WHO \& UNICEF, 2017) in Mumbai's informal settlements, very high housing densities, coupled with narrow and 
winding lanes, pose significant impediments for the provision of sewage systems, and thus, having a toilet at home. In addition, deficiencies in the housing and slum policies of the city, complex land ownership patterns, insecure land tenure and other constraints often complicate actions initiated by municipal service providers (Sarkar \& Moulik, 2006). As a result, people living in these informal neighborhoods are forced to depend on public or communal toilets to meet their sanitation needs.

Over the last four decades, as a supplement to building large citywide, networked infrastructure, Mumbai's response to the demand for urban sanitation facilities for slum dwellers has been through provisions of 'free-for-use' and 'pay-and-use' shared toilet blocks (communal and public) provided by both government and international aid programs. Although the city government has implemented various schemes and projects through the years, and accessibility to shared toilets stands today at 64.1\% (Desai, 2014), public services have not been able to meet the full sanitation needs of slum communities. This deficiency poses serious public health and environmental risks for the entire city's population (Sarkar \& Moulik, 2006).

Since the declaration of the Swachh Bharat Mission (SBM), also known as Clean India Mission, in 2014, with the goal of eradicating open defecation (OD) by October 2019 (MHUA GOI, 2014), the Brihanmumbai Municipal Corporation (BMC) constructed numerous toilet blocks, declaring in 2018 their intention to construct 22,774 new communal toilets by 2021. (Mumbai Mirror, 6.9.2018). However, it is unclear if there have been any formal studies of the communal toilet blocks built under the SBM since 2014. Despite the SBM's declarations and efforts, the actual number of community toilets is way below the standards set by government agencies and international aid organizations. In 2018, nearly 5 million residents of Mumbai's notified slums used 26,379 toilets, an average of 190 users sharing 1 toilet (Desai, n.d.). These figures contrast greatly with the regulations set by the Indian Ministry of Urban Affairs and Employment, and the UNDP-World Bank Water And Sanitation Program which mandate 1 toilet for 50 users or less (WSP, 1995), and those of the UN Refugee Agency, who's sanitation related indicators in post-emergency situations require 1 toilet for 20 users or less (UNHCR, 2019).

This lack of access to facilities as well as conditions inside toilet blocks, which are mostly very poor and sometimes hazardous (Nambiar et al., 2016), create highly polluted environments, expose residents to illness and diseases (McFarlane, 2008) and encourage people to practice OD. Children, who make up $26.2 \%$ of urban India's population (Indian Ministry of Statistics and Programme Implementation, 2018), suffer the most from these low hygiene conditions, not only because they often fall sick and miss school, but also because illnesses caused by poor sanitation affect their growth and development. (Doron \& Jeffrey, 2014). Finally, cultural and social enabling environments can greatly determine children's usage of sanitation services and consequently, contribute to better health and future prospects (Bartlett, 2005). For example, adults' messages, expectations and behavior can affect children's perceptions and habits.

This research was initiated with the objective of studying user environments inside urban India's shared sanitation facilities. It evolved into an exploration specific to children's behavior and the related social and cultural aspects. It aims to describe the overall conditions and usage patterns in 4 community toilets in slums across 2 settlements in 
Mumbai and to document issues affecting children's usage of community toilets. The paper also suggests possible interventions to mitigate and improve children's inclusion and access to these sanitation spaces.

\section{Methodology}

In the State of Maharashtra, only 39.9\% of slum households have toilet coverage and its capital Mumbai has the largest slum population in India, with around $42 \%$ of the city's inhabitants living in informal settlements (MHUPA GOI, 2015). Accordingly, Mumbai was chosen for the field-research and surveys.

The research involved secondary data collection about the demographics of the region, history of community toilet movement, cultural beliefs and norms, and current sanitary regulations and standards, as well as primary data collection from communal toilet facilities within 4 informal settlements of Mumbai and the surrounding communities. The duration of study was 18 months, between April 2017 and September 2018.

The authors began by visiting 11 communal toilet blocks in 4 informal settlements of Mumbai, namely Dharavi, Nagwadi-Chembur, Santacruz, and Garib Nagar-Bandra; documenting their spatial conditions and user experiences. Location, physical structure, maintenance procedures, perceived safety amongst users, and numbers of males, females and children using the facilities, were assessed. Seven community toilet blocks were short listed, in 3 neighborhoods for further observation and comparison. In the next stage, 4 community toilets blocks (2 'free-for-use' and 2 'pay-and-use' toilet models) with comparative similarities were identified in Nagwadi-Chembur and Garib Nagar-Bandra slums.

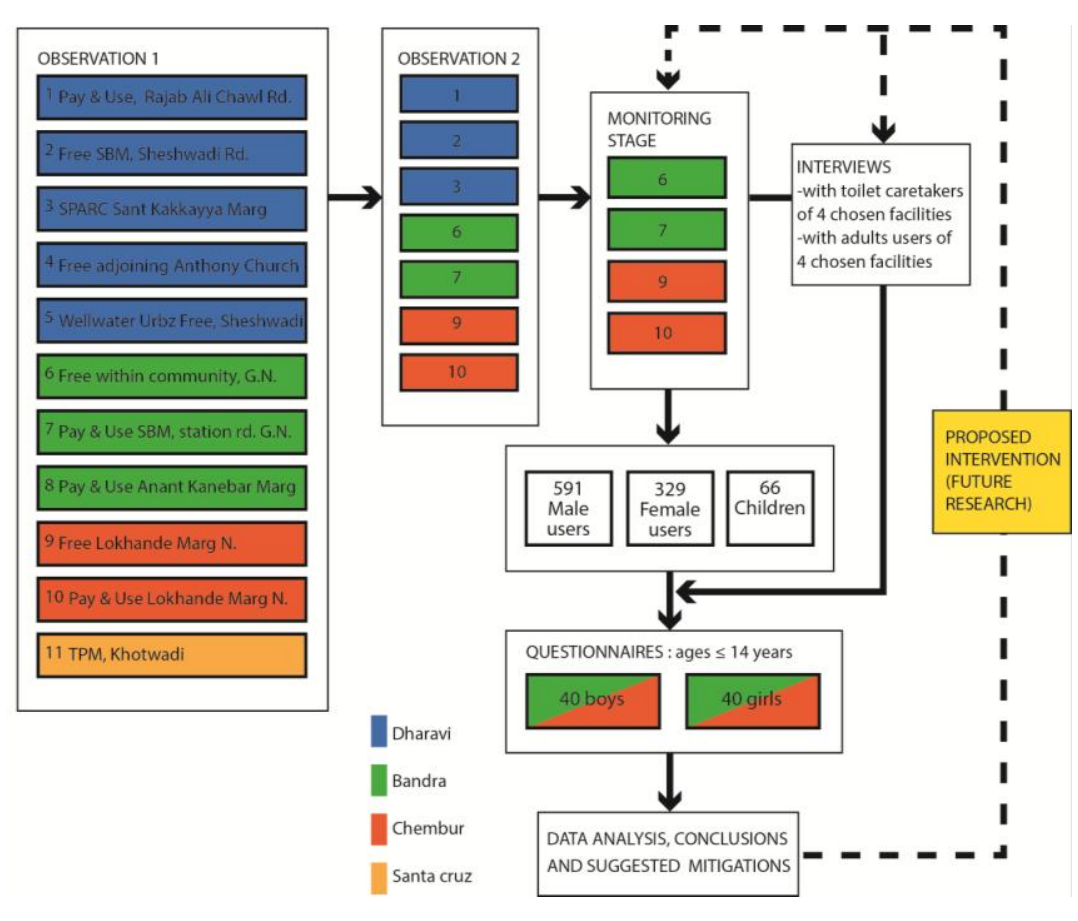

Figure 1: Research methodology for measuring children's usage of communal toilets 
These 4 toilet blocks were further studied to measure natural and physical conditions (light, ventilation, thermal and olfactory comfort), cleanliness, internal dimensions of stalls and, in the case of pay-and-use toilets, financial models. Usage patterns were monitored on busy weekdays, between $7 \mathrm{am}$ to $9 \mathrm{am}$ - when the usage is usually at its peak, as informed by the toilets' caretakers and users. Random interviews with adults around the facilities were also conducted.

During the course of the study, the data collected revealed that only $6.7 \%$ of the users were children 14 years old or younger - a much lower percentage than the 2011 India census data which showed that they comprise about one-fourth of Mumbai's population. The authors then decided to conduct individual interviews, using questionnaires with 80 children (6-14 years old). A compendium of 26 multiple-choice questions and 10 openended questions were asked in an informal conversation. The purpose of the questionnaire was to understand the socio- cultural context, children's perception of the sanitation solutions available to them, and possible ways to promote community toilet use. Two specific sites in Chembur and Bandra were selected for the interviews for the following reasons:

1) A relatively higher number of children were observed using facilities in these 2 sites

2) Visual proximity to both 'free-for-use' and 'pay-and-use' toilet models, and an OD site.

3) A neutral zone for observation, which ensured a fair understanding of where children were going and for what purpose.

\section{Main Findings and Analysis}

\subsection{Neighborhood water and sanitation's landscapes}

In Garib Nagar-Bandra and Nagwadi-Chembur, most residents share water points on the main municipal water plumbing line, laid in the alleys outside their houses. These taps supply water for 2-4 hours twice a day. Most houses have a mori - a designated sunken spot with a floor drain (trap) where residents bathe, wash their utensils or vegetables, and sometimes urinate. The grey water from these activities, drains out through a narrow PVC pipe into an alley canal (gutter) - usually covered with concrete slabs, but may also be exposed at some spots. Some houses, with floor levels below gutter level, cannot designate a space for a mori and are forced to bathe outside in the alley. During the monsoon season, when many gutters overflow, the contaminated water threatens to spill into the interiors of these houses. Defecation continues to be a huge problem for a majority of the population, since none of the households have attached indoor toilets, and they are not connected to a drainage pipeline or a waste treatment system. Consequently, adults and children rely on shared toilet facilities public, communal or institutional (schools, offices, workshops) - and practicing OD.

\subsubsection{Usage Patterns}

Although $81.3 \%$ of children interviewed expressed their aspiration to have a toilet inside or adjacent to their home, for reasons of convenience and potential cleanliness, none of them did. This reality positions shared communal toilets as an indispensable option for residents. Still, this research revealed that a very low percentage 
of children within the society were consistently using these facilities. Only $10 \%$ of female users were girls and $4.7 \%$ of male users were boys. Furthermore, the results also revealed a gender gap in community toilet usage with the percentage of girls reporting to 'never practice OD' almost double that for boys $(77.5 \%$ and $37.5 \%$ respectively).

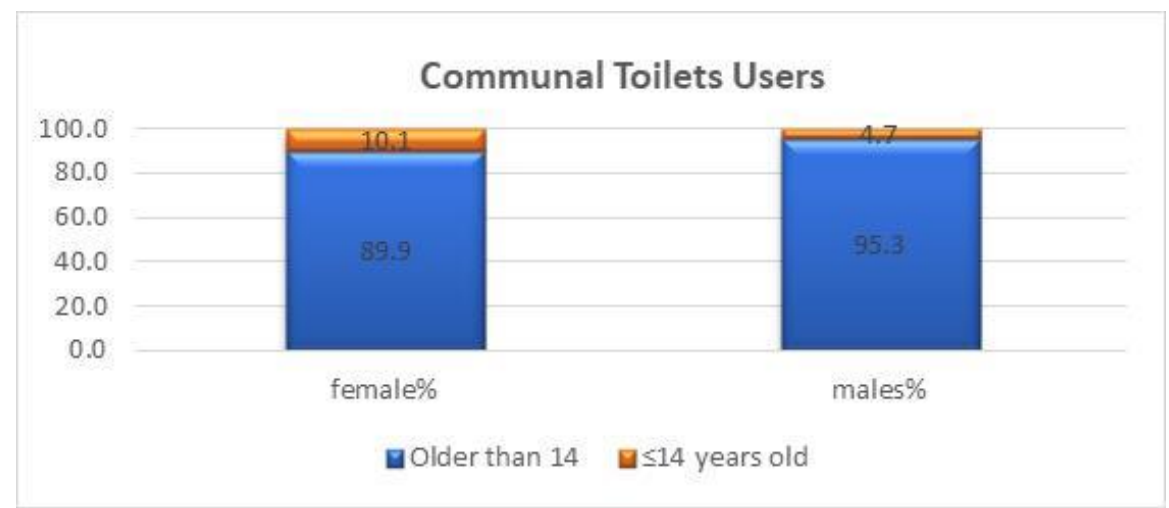

Figure 2: Toilet usage by children as a percentage of total communal toilet users

For urination, although most children preferred using the mori in their home, boys reported urinating in the open 3 times more than girls. Of the girls interviewed, 15\% admitted to urinating in the open as compared to $52.5 \%$ of the boys. The reasons cited for not using the mori were: guests at home or needing to urinate while being outside (playing with peers).

\subsubsection{Physical conditions}

None of the sanitation facilities had children sized pans (Indian squatting-type commode) to fit their anthropometry. In addition, conditions inside the 4 toilet facilities were below acceptable communal standards according to the adults and children surveyed. Floors were often dirty and wet, and some of the pans, were clogged and did not function. The toilet interiors were mostly odorous with foul smell of feces and cigarette smoke; some stalls had red stains of Betel leaf spit in corners; and in the absence of dustbins, used sanitary pads were spotted carelessly discarded behind doors. Consequently, $72.5 \%$ children referred to the toilet facilities they use as 'dirty', whereas $82.5 \%$ complained of 'foul smell'. Further, when asked what their 'dream toilet' would entail, $42.5 \%$ of the children, answered, 'clean' as a major characteristic. Children also admitted that they found the stalls dark, even during daytime, due to the small sized and often-blocked ventilation shafts. 


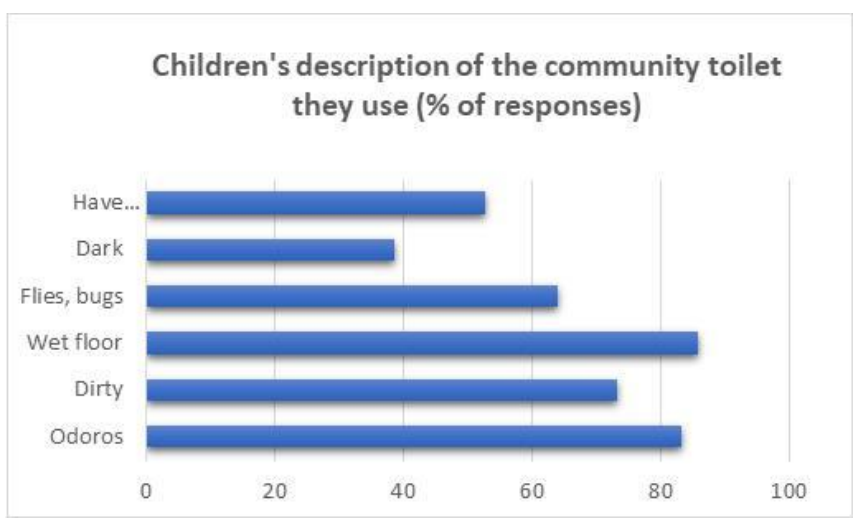

Figure 3: Survey response about toilets indoor conditions

\subsubsection{Water Availability}

Water is a crucial necessity in India's anal cleansing culture. People do not use dry wipes to clean after themselves, but instead, wash after defecating. Therefore, in this 'washers' environment, the current lack of water plumbing lines in the 'free-for-use' communal toilets, forces people to haul water physically to wash themselves. Out of all users of 'free-for-use' communal toilets surveyed, $86.4 \%$ carried water in small buckets when entering these facilities. Children found the act of carrying a bucket of water for spectators to see and cueing at their intended destination embarrassing. This notion was highlighted by $56.1 \%$ children who emphasized the availability of water in their 'dream toilet'. Those using 'pay-and-use' toilets did not carry buckets filled with water, since the availability and usage of water is predominantly what makes the facility a 'payable' one.

\subsection{Enabling social and cultural environment}

Due to the abysmal ratio of toilets to users, and the physical conditions in the 4 sanitation facilities, children often favor OD over using community toilets. In addition, in most of India, young children's excreta are considered less disgusting and contaminating than that of adults. It is socially acceptable for children 3 years-old and younger, to defecate inside the home or right outside the door on a piece of paper or cloth, that can later be lifted and quickly disposed in a waste bin, much like a diaper. (Routray, Schmidt, Boisson, Clasen, \& Jenkins, 2015). On the contrary, children's feces is more perilous than adults due to a higher prevalence of diarrhea and pathogens in children (Rand, Loughnan, Maule, \& Reese, 2015). In both Nagwadi-Chembur and Garib Nagar-Bandra, the authors observed children as old as 5 years old practicing OD in exposed alleyways next to their home. Such norms and beliefs discourage the usage of available sanitation facilities.

\subsubsection{Peer Impact}

Beyond the cultural sphere, peers are a strong influence on behavior (Lawrence et al., 2016) and going with friends to relieve bodily waste was observed in both slums. A few boys mentioned in the interviews the fact that 'not being able to socialize' with friends was a negative point against toilet usage. Further, practicing OD seems to be a 
social activity for both genders. Going in the open with friends is more common than going to the toilet with friends, and does not seem to be a precaution for safety issues; roughly half of the children who go with friends to OD admitted to being "scared" of darkness and the same was true for toilet users.

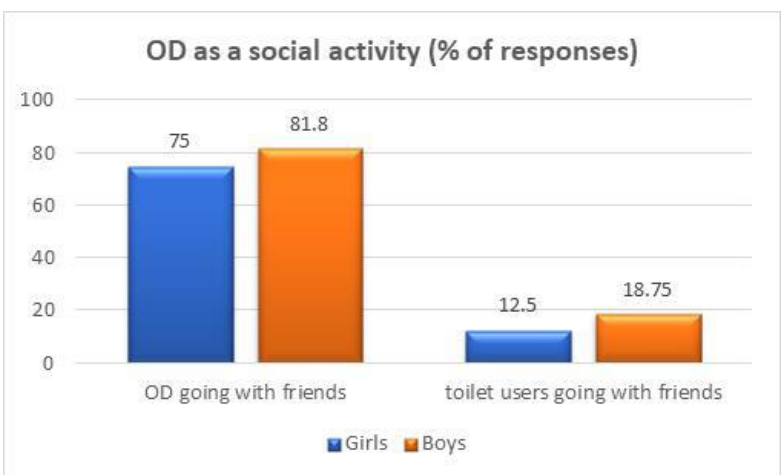

Figure 4: Gender based comparison: Influence of peers on toilet usage vs. OD patterns

\subsubsection{Parental influence}

Parents and guardians appear to play an important role when it comes to sanitary behavior: all children who were toilet users reported that their parents and other adults within their household were toilet users as well. Consequently, $85 \%$ of children admitted that their parents wanted them to use toilet facilities, however $59.4 \%$ of answers didn't associate OD with a sense of disobedience or violation of rules. This notion is reinforced by the fact that only $43.3 \%$ of the children practicing OD felt "embarrassed" to be seen walking towards OD designated areas.

Among families, there seems to be a gender disparity in the willingness to give children money for using 'pay-and-use' toilet facilities. According to the interviewees, parents were less inclined to give girls a budget for their sanitation needs as compared to boys $42.5 \%$ of girls reported to 'never receive money' from their parents, compared to $27.5 \%$ of boys. Regardless, girls were more prone to use sanitation facilities, be it the 'free-foruse' toilets, 'pay-and-use' toilets, school toilets or other.
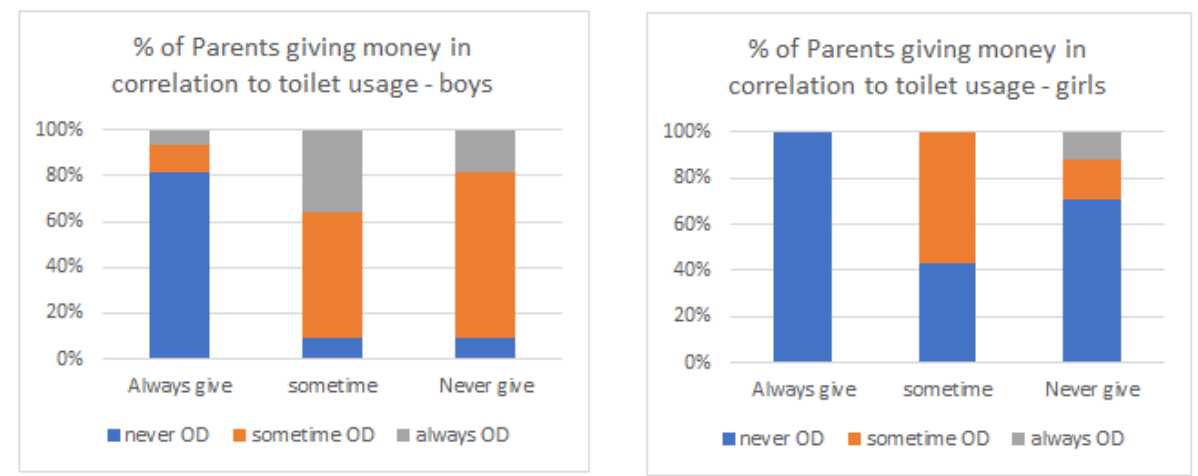

Figure 5: Children's report of money for 'pay-and-use' toilets received from parents 


\subsubsection{Community's influence}

Outside the home, the neighboring community does not seem to support and promote children's usage of toilet facilities. Interviews revealed that adults found children using the toilets 'a nuisance' since they took more time and left the stalls dirty and foul. Some adults also admitted to occasionally shooing children away, directing them to the OD sites. In parallel, the children's account of some of the major reasons 'not to like the toilet' were adults inside the facilities 'rushing them to come out', 'shouting' and 'banging on doors'. These behaviors compound the already poor conditions of the community toilets, making them even less desirable for children.

What children "hate about the toilet"

(\% of responses)

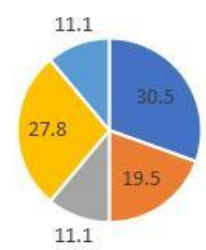

- crowded $=$ adults discouragement $\|$ dark $=$ dirty, stuffy, smelly $\approx$ not social

Figure 6: Deterrents to children's toilet usage experience.

\subsubsection{Perceived gender differences towards OD}

Gender differences were exposed through questions regarding social expectations of toilet usage. As articulated by children, $26.3 \%$ of both genders expressed that it is acceptable for boys to practice OD while only $6.3 \%$ held the same opinion towards girls. This is reinforced by the fact that among children with siblings, 25\% reported that their brothers practiced OD while only $4.8 \%$ reported that their sisters practiced the same.

\subsubsection{SBM influence}

Since 2014, efforts by the government towards the Swachh Bharat Mission (SBM), have been conveyed through local authorities, schools, communities and the media, which have been continuously exposing the Indian population to the importance of eradicating OD and promoting safer sanitary behavior. Indeed, 86.1\% of children interviewed, reported that they were exposed in school, at home or on TV to messages promoting toilet usage. However, the continuing high rates of OD among children in the areas surveyed makes it evident that these messages do not sufficiently materialize into action. In fact, the findings bring into question the campaign's effectiveness in influencing children to use sanitation facilities exclusively.

\section{Conclusions and Suggested Mitigations}

Toilets are where the private meets the public realm (Penner, 2013). Consequently, the communal toilets' scene in Mumbai's slums, can be considered as a 
barometer to the infiltration of the SBM message to eradicate OD. Although the mission represents a positive step towards achieving SDG 6.2, in the absence of a formal policy regarding children's explicit entitlement to using toilets, and in keeping with socially acceptable norms, the interpretation and implementation of this fundamental right has been left to the discretion of communities and parents/guardians at large.

The primary findings of this study reveal a shockingly low usage of community toilets by children, and indicate that the physical realities and the mental, social and cultural domains seem to be lagging behind the SBM 2019 goal. The deficiencies in sanitation facilities and water systems and the physical conditions inside toilets do not meet community standards, and thus are not fully used by the population it was intended to serve. Community toilet spaces do not provide a positive user experience and do not support young users' need to socialize. Norms such as the acceptance of OD by young children, convey the notion that it is 'ok' not to use toilets. Girls are financially discriminated against, receiving less money from their parents than boys to use better (water connected) community toilet facilities. Adults' self-interested behavior jeopardizes the OD-free message, creating a confusion in children's minds between what is expected and what is accepted. Still, the fact that the majority of children wish to have a toilet at home and understand the benefits of using a safer option, indicates that the SBM message is penetrating society's younger members minds and changing the cultural scene.

In conclusion, in order for children to change their sanitary behavior towards invariably using community toilets, both the lack of acceptable facilities and the confounding cultural and social spheres, must be addressed. In terms of reducing physical barriers, governing bodies should establish building bylaws that mandate builders to include a few designated stalls in communal and public facilities that meet children's ergonomic requirements. Once built, these stalls could have signs designating them as 'child friendly'. There is a wealth of literature concerning child-appropriate toilet designs, such as those found in official manuals from the Indian Ministry of Drinking Water and Supply's 'School and Anganwadi Toilet Designs- Norms and Options Manual' (DWS GOI, 2004), and in UNICEF publications.

In order to address cultural norms and encourage society's admittance of children into sanitation spaces, the authors suggest a community led action - posting, widely visible signage on toilet facilities which will welcome children and assert their rights as users. A follow-up study is planned to evaluate the effectiveness of the children-specific signage intervention using this research as a baseline. Using the same questionnaires, we will observe whether these signs can serve as a validation to children's presence in communal sanitation spaces, and convey a message of their inclusion to parents, the surrounding community and to the children themselves. Finally, by addressing the issues raised in this paper the authors anticipate that children will experience a safer, more hygienic environment, which will lead to reduced illness, absenteeism from school and, ultimately, a better chance at growth and advancement. 


\section{References}

Bahadure, P., \& Bahadure, S. (2012). International Conference on Advances in Architecture \& Civil Engineering (AARCV 2012). Sustainable Urban Development in India: Challenge \& Approaches, 2012(21-23, June), 712-720. from https://www.academia.edu/6305081/Sustainable_Urban_Development_in_India_Challenge_and Approaches

Bartlett, S. (2005). Water, Sanitation and Urban Children. The Need To Go Beyond Improved Provision, 15(1), 115-137. Retrieved

from

https://www.jstor.org/stable/10.7721/chilyoutenvi.15.1.0115?\&seq=1\#page_scan_tab_contents

Desai, D. (n.d.). Sanitation problems in Mumbai at catastrophic proportions. Retrieved from https://www.orfonline.org/expert-speak/42671-sanitation-problems-in-mumbai-at-catastrophicproportions/

Desai, P. (2014). Sanitation in Slums of Mumbai View from the Field. Ahmedabad. Retrieved from http://www.pas.org.in/Portal/document/PIP Application/Sanitation Report Padma Final.pdf

Doron, A., \& Jeffrey, R. (2014). Open Defecation in India. Economic \& Political Weekly, 49(49), 72-78. Retrieved from http://www.epw.in/system/files/pdf/2014_49/49/Open_Defecation_in_India.pdf

DWS GOI. (2004). School and Anganwadi toilet design-technical note series. Department of Drinking Water and Sanitation, Government of India. Retrieved from https://mdws.gov.in/sites/default/files/SchToiletDesign_1.pdf

Lawrence, J. J., Yeboah-Antwi, K., Biemba, G., Ram, P. K., Osbert, N., Sabin, L. L., \& Hamer, D. H. (2016). Beliefs, behaviors, and perceptions of community-led total sanitation and their relation to improved Sanitation in Rural Zambia. American Journal of Tropical Medicine and Hygiene, 94(3), 553562. Retrived from https://www.ncbi.nlm.nih.gov/pmc/articles/PMC4775890/

McFarlane, C. (2008). Sanitation in Mumbai's informal settlements: State, "slum", and infrastructure. Environment and Planning $A, \quad 40(1), \quad 88-107 . \quad$ Retrived from https://journals.sagepub.com/doi/10.1068/a39221

MHUA GOI. Swachh Bharat Mission -Urban Guidelines (2014). Ministry of Housing and Urban Affairs, Government of India. $\quad$ Retrieved from http://swachhbharaturban.gov.in/writereaddata/SBM_GUIDELINE.pdf

MHUPA GOI. (2015). Slums in India. A Statistical Compedium 2015. Ministry of Housing and Urban Poverty Alleviation, Government of India, National Buildings Organisation. Retrived from http://nbo.nic.in/Images/PDF/SLUMS_IN_INDIA_Slum_Compendium_2015_English.pdf

Ministry of Statistics and Programme Implementation, Social Statistics Division, \& Government of India. (2018). Children in India 2018, 1-147. Retrieved from http://www.mospi.gov.in/sites/default/files/publication_reports/Children in India 2018 - A Statistical Appraisal_26oct18.pdf

Ministry of Women and Child developement. (2013). National policy for children. The Nursing Journal of India. New Delhi: ministry of women and child development, Government of India, UNICEF. Retrived from https://wcd.nic.in/sites/default/files/RSOC\%20National\%20Report $\% 202013$ $14 \% 20$ Final.pdf

Mumbai Mirror 6.9.18. (, September). BMC to go vertical. Mumbai Mirror 2018. Retrieved from https://mumbaimirror.indiatimes.com/mumbai/civic/bmc-to-go-vertical-with-communitytoilets/articleshow/65694553.cms

Nambiar, D., Ganesan, P., Rao, A., Anand, G., Wankhade, K., et al. (2016). India Exclusion Report 2015. Retrived from http://www.im4change.org/docs/91763text-final_India-Exclusion-Reportround2Final.pdf

Penner, B. (2013). Bathroom (Objekt ser). London: Reaktion Books Ltd. Retrieved from http://www.reaktionbooks.co.uk/display.asp?ISB=9781780231938

Rand, E. C., Loughnan, L. C., Maule, L., \& Reese, H. E. (2015). Management of Child Feces: Current Disposal Practices. Water and Sanitation Program: Research Brief, (June), 8 pp. Retrieved from https://www.wsp.org/sites/wsp.org/files/publications/WSP-CFD-Summary-Brief.pdf 
Routray, P., Schmidt, W. P., Boisson, S., Clasen, T., \& Jenkins, M. W. (2015). Socio-cultural and behavioural factors constraining latrine adoption in rural coastal Odisha: An exploratory qualitative study Global health. BMC Public Health, https://bmcpublichealth.biomedcentral.com/track/pdf/10.1186/s12889-015-2206-3

Sarkar, S. \& Moulik, S. G., (2006). The Mumbai Slum Sanitation Program: Partnering with Slum Communities for Sustainable Sanitation in a Megalopolis, (September) 2006. http://documents.worldbank.org/curated/en/620841468041130033/pdf/384560IN0Mumbai0slu m01PUBLIC1.pdf

UN-Habitat. (2016). Slum Almanac 2015-2016: Tracking Improvement in the Lives of Slum Dwellers. Participatory Slum Upgrading Programme. (Vol. s4-XII). https://unhabitat.org/slum-almanac-2015-2016/

UN-Habitat. (2014). World Habitat Day - Voices from Slums; October 6, 1-6. Retrieved from http://unhabitat.org/wp-content/uploads/2014/07/WHD-2014-Background-Paper.pdf

UNHCR. (2019). Emergency sanitation standard, 1-4. Retrieved from https://emergency.unhcr.org/entry/248594/emergency-sanitation-standard

UNDESA-United Nations, Department of Economic and Social Affairs, P. D. (2014). World Urbanization Prospects. https://esa.un.org/unpd/wup/publications/files/wup2014-highlights.pdf

World Health Organization, CSDH. (2008). Closing the gap in a generation. Retrieved from https://www.who.int/social_determinants/final_report/csdh_finalreport_2008.pdf

World Health Organization \& UNICEF. (2017). Progress on drinking water, sanitation and bygiene: 2017 update and SDG baselines. Retrieved from https://apps.who.int/iris/bitstream/handle/10665/258617/9789241512893eng.pdf?sequence $=1$ \&is Allowed $=\mathrm{y}$

WSP. (1995). Guidelines on Community Toilets, (April), 1-86. Retrieved from https://www.wsp.org/sites/wsp/files/publications/320200734151_guidelinesoncommunitytoilets .pdf 